\title{
A MANAGEMENT APPROACH TO COMPONENT OBSOLESCENCE IN THE MILITARY ELECTRONIC SUPPORT ENVIRONMENT
}

\author{
A. Meyer ${ }^{1}$, L. Pretorius ${ }^{2}$ and J.H.C. Pretorius \\ ${ }^{2}$ Faculty of Engineering \\ Rand Afrikaans University (RAU), South Africa \\ meya@,kidd.co.za, 1 p@,ing.rau.ac.za
}

\begin{abstract}
This article proposes a process to manage the problem of electronic component obsolescence from a military product support perspective. By assessing applicable literature as well as feedback and lessons learned from relevant support projects, a methodology for the management of component obsolescence is proposed. The aim of the research is to provide a definition of component obsolescence drivers and to formulate a process for the management of component obsolescence within a military electronic support environment. The process provides guidelines on how management activities can be optimised to reduce applicable obsolescence risks and thereby reducing related life cycle costs.
\end{abstract}

\section{OPSOMMING}

Hierdie artikel stel ' $n$ proses voor hoe om die probleem van onbeskikbaarheid (uitgediendheid) van elektroniese komponente in die militêre steunomgewing te bestuur. Toepaslike literatuur asook terugvoer en lesse geleer uit toepaslike steunprojekte is ondersoek ten einde ' $\mathrm{n}$ proses voor te stel om die onbeskikbaarheid van elektroniese komponente te bestuur. Die doel van die navorsing is om drywers te identifiseer wat aanleiding gee tot onbeskikbaarheid van elektroniese komponente in die militêre steun omgewing en om ' $\mathrm{n}$ proses te bepaal om hierdie probleem en risiko's te bestuur. Die proses bied riglyne hoe bestuursaktiwiteite geoptimaliseer kan word om beskikbaarheidsprobleme te beperk en dus ook lewensikluskoste van elektroniese stelsels en projekte te verminder.

\footnotetext{
${ }^{1}$ The author was enrolled for the MPhil (Engineering Management) at the Engineering Faculty, Rand Afrikaans University (RAU)
} 


\section{INTRODUCTION}

\subsection{Scope of the research}

This article reviews the fundamental causes of component obsolescence and approaches to manage the problem of obsolescence. A proposed methodology has been formulated to manage component obsolescence in a military electronic support environment. This is supported by conclusions and recommendations on the subject of component obsolescence management. Specific emphasis is placed on applicable case studies and appropriate lessons learned from these case studies.

The following criteria have been chosen to achieve the goal of managing the problem of component obsolescence:

- To investigate, assess and evaluate literature on component obsolescence and related case studies, with the aim of identifying the main drivers of component obsolescence and lessons learned.

- To identify key tasks to minimise the effect of component obsolescence, and to propose a process to manage electronic component obsolescence (in the military environment).

- To ensure that designers take note of the effect that their design decisions have on the system under development, or during design upgrades or modifications.

- To ensure that system life cycle costs are optimised through good design choices as well as by implementing sound procurement and materials management processes and team interfaces.

- To provide an environment where obsolescence management is an integral part of the system engineering process, thus mitigating the effect of component obsolescence.

Activities have been identified that will ensure the cost-effective implementation of an obsolescence management programme. Some related topics for further research have also been included.

\subsection{Problem definition}

The problem of component obsolescence was found to affect all products and equipment throughout the total life cycle of a product or system and is not limited to certain types of hardware, but it includes testing and support equipment, software, tools, processes, logistic products, standards and specifications. [1] A key finding is that the problem of component obsolescence cannot be ignored during development and design, or during the through life support (TLS) of the product or system. The consequences, if they are ignored, are expensive and time-consuming to mitigate or to effectively address it.

For purposes of the research, the problem of component obsolescence was defined as, 'the loss of, or in process of losing, the last known supply or availability of an item or component'. In other words, a particular item or component will no longer be produced, or be available 
from own spares stock, or be procurable from its last-known supplier or original equipment manufacturer (OEM).

It was found that the problem and nature of component obsolescence and obsolescence management have not been well understood by private industry, as well as managers of weapon systems, until fairly recently. Managers often tend to address the problem in a reactive mode, and attempt to correct the problem by implementing 'quick fix' solutions. Another incorrect assumption identified was that component obsolescence could be attributed to poor logistic management. Component obsolescence was also often viewed as a prime reason for a redesign or upgrade of the equipment or system.

\subsection{Importance and consequences of the problem of component obsolescence}

Component obsolescence has become a major cost driver in the through life support of electronic equipment and systems and is becoming the single biggest technical risk impacting on their operational availability and maintainability. Delaying preventative management actions to address this problem often results in premature phasing out of systems due to the inability to respond to operational readiness and availability requirements of the affected systems. Various examples and case studies from literature demonstrate the financial risk and impact of component obsolescence. [20]

Although component obsolescence can be applicable to almost any type of component-related to electronic equipment and systems, this article focuses primarily on electronic component obsolescence in the military support environment. Component obsolescence has been found to happen too frequently and costs too much to be ignored. [1] The financial risk and impact of component obsolescence are demonstrated by the following examples as applicable to various sectors in the military and related environments;

- 'Obsolescence is also very expensive, costing the US Navy (USN) hundreds of millions of dollars each year.' [1]

- 'The Deputy Under Secretary of Defence for Logistics (USA) indicates that the average cost to redesign a ( single) circuit card to eliminate obsolete components is \$250,000.' [4]

- 'The (USA) Air Force is reprogramming $\$ \mathbf{8 1}$ million for the F-22 program to purchase obsolete or soon-to-be out-of-production parts and to redesign assemblies to accept commercial parts.' [4]

- 'An avionics manufacturer for the commercial airlines spent $\$ \mathbf{6 0 0 , 0 0 0}$ to replace an obsolete Intel chip.' [4]

- 'The F-16 program has spent $\mathbf{\$ 5 0 0}$ million to redesign an obsolete radar.' [4]

\section{LITERATURE SURVEY}

\subsection{Scope of the literature survey}

Literature on the subject of component obsolescence can be found mainly in articles, 
specifications and procedures, as well as conference papers of institutions or organisations that have an interest in the management of component obsolescence. The literature survey has studied two main subjects, namely contributing factors to electronic component obsolescence, and current practices in the management of obsolescence.

\subsection{Review of the literature survey}

The objective of obsolescence management as identified in the literature is to ensure that obsolescence is managed as an integral part of design, development, production and in-service support of projects or systems in order to minimise its cost and impact throughout the product life cycle. It was found that a reactive approach to manage component obsolescence was followed and that it was aimed predominately at finding short-term solutions. These reactive activities were normally performed at a specific time as the problems occur and are often continually being repeated throughout the life of the programme.

It was established that new projects increasingly rely heavily on commercial components and associated software $(\mathrm{S} / \mathrm{W})$. The current rapid advances in $\mathrm{S} / \mathrm{W}$ development and dedicated requirements that this modern $\mathrm{S} / \mathrm{W}$ enforces create a situation where the $\mathrm{S} / \mathrm{W}$ technology is driving hardware $(\mathrm{H} / \mathrm{W})$ design and technological advances. [17]

Managing the risks of obsolescence was emphasised in the literature as an important task for all projects, especially those that are complex, have a long operating life cycle, or that contain a high $\mathrm{S} / \mathrm{W}$ element or interface. The reason for this is that the markets continuously demand devices that are faster, smaller, use less power and offer improved user interfaces. To aggravate the situation, there is an increasing competitive pressure on the commercial market. Extraordinary numbers of relatively small customers encourage novelty, so upward compatibility with existing $\mathrm{S} / \mathrm{W}$ is not a high priority and consequently, the result of no upward compatibility is the obsolescence of existing $\mathrm{S} / \mathrm{W}$ and in many cases also the related $\mathrm{H} / \mathrm{W}$.

Obsolescence management strategies can be considered and implemented at various levels. The most effective management levels identified were related to engineering activities and procurement that included materials management activities. At the earliest stages of a project, the project manager should produce and implement an Obsolescence Management plan (OMP). [5] Applicable strategies to evaluate obsolescence risks, as well as corrective actions required for consideration throughout the total life cycle of products or systems should be documented in the OMP. The interrelationship of $\mathrm{H} / \mathrm{W}$ and $\mathrm{S} / \mathrm{W}$, as well as the impact and long-term support consequences of using commercial off-the-shelf (COTS) components instead of military specification components in military applications, should be considered thoroughly by engineers and logisticians. The reason for this is that COTS components are very much affected by fast-changing market preferences that in many cases lead to early production termination of these COTS components. Reliability considerations of COTS components are often also scaled down in favour of commercial considerations. Strategies to mitigate the risks of obsolescence should be managed as a team and not as individual attempts that lack transparency or communication to related projects and other related areas of interest. [7]

Commercial markets in the computer, telecommunications, and consumer industries dominate markets for semiconductor devices. The market share of the military sectors in 2001 was less 
than $0,4 \%$ from a 316 billion USD semiconductor component market. [2,3] It is also clear from the literature that the transition from the military specifications (MIL-P-50884C and MIL-PRF-31032) to the commercially accepted standard (IPC-6013) [15] has had a considerable impact on the utilisation of commercial components instead of military specification components.

The increase in safety and environmental legislation has affected the use of some materials and substances in the manufacturing and production of various types of electronic equipment and component. [5] The literature established that large ranges of electronic components were terminated or in the process of being phased out. It was concluded that these restrictions and controls contributed to the availability of components and component obsolescence.

The literature survey also indicates that military systems typically require a 20 -year spares supply support, but that the typical life cycle for recently introduced logic family parts is three years and eight years for passive components. [10] Semiconductor components were viewed as being one of the highest impact/risk electronic component types used in avionics and military assemblies. It is evident from Figure 1 [3] that the life cycle mismatch between systems and technology and the implications of using commercial off-the-shelf (COTS) components are increasing.

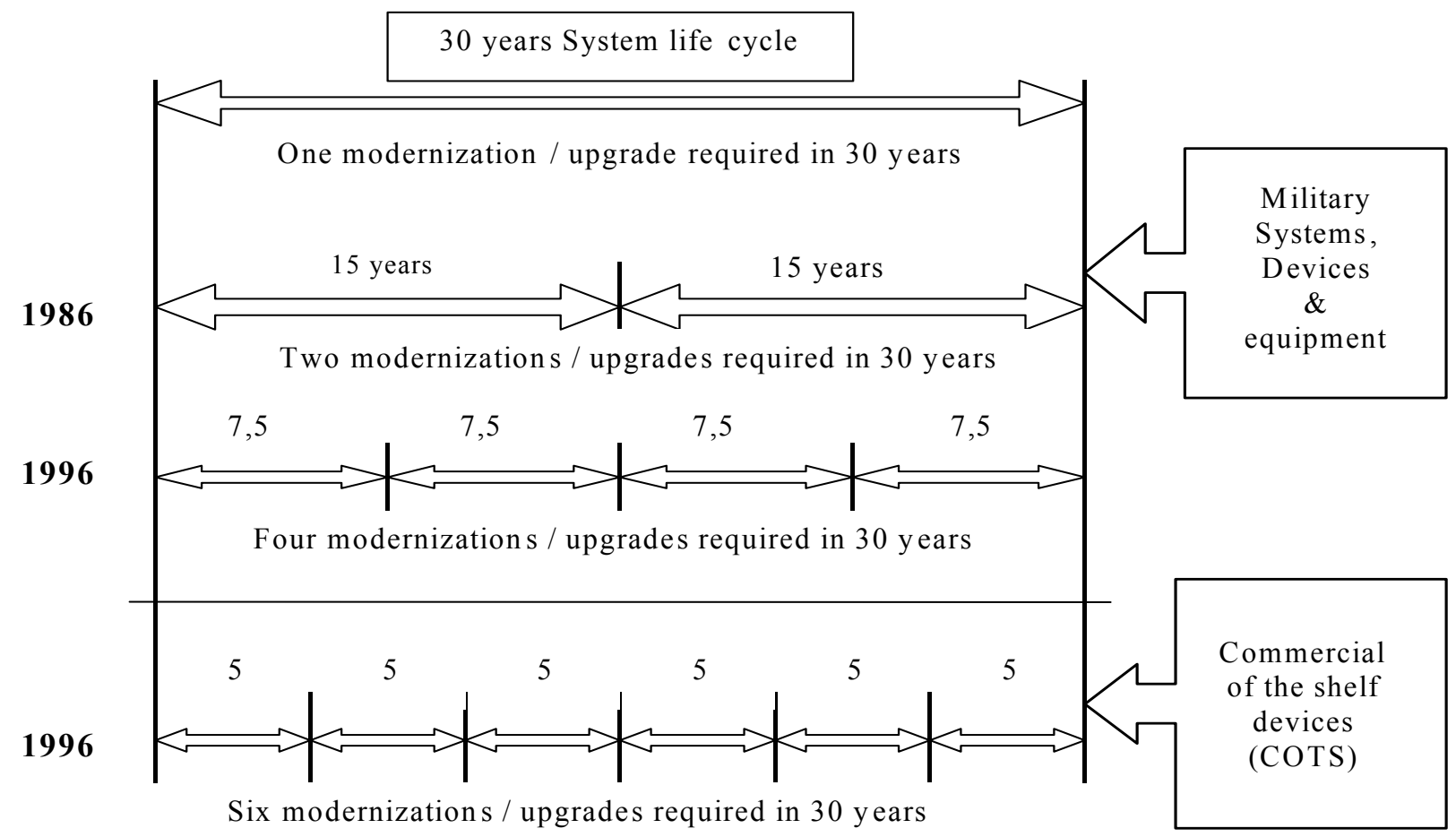

Note: Lifecycles can even be shorter in today's markets

Derived from original source TACHtech [3]

Figure 1: Difference in life cycles of military and COTS equipment [3]

Poor selection of electronic components by designers compromises reliability of systems and also adversely affects availability, especially during the support phases of products. Specific obsolescence problems and issues are in many cases not openly debated. Only in the past decade did defence industries, organisations and military departments start to share 
information and to structure themselves into teams and groups to address common obsolescence problems. These groups have started to interface more and more by utilising Internet web sites [12].

Several case studies from literature, as well as applicable case studies from the support environment in which the author [18] is employed, have been assessed in order to develop a strategy to manage component obsolescence in the military environment. The benefit of having the support of an obsolescence management team to find the most cost-effective technical solution for obsolescence problems has been effectively demonstrated by these case studies.

Successes reported by companies and programmes that have implemented obsolescence management processes are well documented in the literature. It became evident that obsolescence management is an important element that should be addressed in the programme plans and system engineering planning in order to support reliability, availability, maintainability, produceability and supportability goals of complex programmes. The proposed obsolescence management methodology has been developed from the literature surveys and lessons learned from case studies.

\section{THE PROPOSED OBSOLESCENCE MANAGEMENT METHODOLOGY}

\subsection{Introduction}

It is not the aim to discuss the basic functions and elements of management in detail in this article. The functions of management that have been considered in formulating and defining the obsolescence management process are; planning; organization; leadership; control; monitoring and corrective actions. It is assumed for purposes of defining the obsolescence management process in this article that electronic component obsolescence will be addressed by established military organizations and related industries and not by small commercial users of electronic components. The functions of management as described above have been integrated in formulating the obsolescence management process and methodology. Management functions and associated actions are being addressed, but not necessarily as unique or independent management elements.

\subsection{Obsolescence management planning and organisation}

The purpose of obsolescence management planning was defined as providing guidance in planning a cost-effective obsolescence management process that takes into account the essential factors to ensure that the product life cycle costs are considered and applied. [5]

First activities to plan should be the establishment and implementation of a work group or teaming group and also to structure or re-organize existing project teams to effectively address and manage obsolescence problems applicable to their projects or environments.

\subsubsection{Implementation of a component obsolescence teaming group}

The Component Obsolescence Teaming Group (COTG) $[9,14]$ should be a formalized group of representatives from military programmes/projects and related industries that work together 
to share solutions and strategies to resolve common component obsolescence problems. By working together to resolve obsolescence issues, military projects and industry can save both time and money by consolidating their requirements and by sharing the cost of implementing such resolutions. The COTG should maintain a database of current information on component obsolescence and, whenever possible, explore resolutions that would work for all related programmes or systems.

\subsubsection{Functioning of the component obsolescence teaming group (COTG)}

The way that the teaming group functions [9] typically includes consideration of obsolescence resolution options when receiving notice(s) of obsolete components from original equipment manufacturers (OEMs) or suppliers. In the case that an OEM decides to discontinue a component, a notice of obsolescence should be sent to distributors, suppliers and to all participating teaming members and importantly, the procuring activity for the affected programmes or specific projects, if it is known.

Once the procuring activity receives a notice of obsolescence, they should compare the notice with their parts database or component list to determine whether the obsolete component affects production or support of any of their specific products, equipment or systems. No action would be required if the component does not affect the equipment, or if it could still be offered by at least one manufacturing source guaranteeing long-term supply. However, if the equipment is affected and no other known sources of supply are available, the procuring activity should provide the allocated part number and the generic part number of the obsolete component to the database maintained by the COTG. An obsolescence case should be established when two or more programmes have been found to use the same obsolete component (identified by the same generic part number). The COTG database representative should notify the applicable participating team members of the fact that an obsolescence case has been established. All available information about the component, (e.g. final order date, minimum order quantity, current inventory levels at participating team members), should be gathered by the team members from their data sources, as well as from the primary equipment manufacturers.

Potential obsolescence solutions should then be considered and implemented by the COTG [9] typically as set out in paragraphs 3.7 and 3.8 below. Each programme representative or procuring activity associated or affected by the obsolete component case should evaluate the COTG data and select the most appropriate solution for his programme requirements and cost constraints. The programme representatives affected by the obsolete component should enter the information about the various solutions, including the associated costs, into the COTG database. The COTG should share obsolescence solution information, as well as applicable cost information related to the solution, with teaming members.

\subsubsection{Establishment of a project team to address obsolescence management}

A project team should be established to address obsolescence management elements. The system engineer, designer and logistic engineering interface should ensure that electronic components are selected and applied properly in the design. [8] Ensuring that the specific types of component as selected for use in the specific environment, e.g. military versus commercial environments, are correctly purchased is the responsibility of the procurement 
interface. The quality of every individual component should be assured by the quality control interface (QA).

Production, maintenance and logistic engineering interfaces should have the combined responsibility to ensure component compatibility with the equipment manufacturing process regarding the integrity of equipment manufacturing, equipment shipping, handling, storage and component shipping, equipment testing, repair, and rework. Programme management and the logistic engineering interface should ensure that a process is in place to make technical data available and to collect, store, retrieve, analyze, and act upon data concerning electronic component problems. The engineering and configuration management interfaces should share the responsibility to ensure that configuration control will be performed by ensuring that electronic components are selected, substituted, and managed systematically to maintain traceability of components, as well as configuration control of specific components fitted in specific equipment.

The project team could consist of the normal members of the project or programme as depending on the life cycle phase e.g. development phase or stable support phase. Final structure and composition of the project team can differ from programme to programme and may be influenced by the organizations' structure that can have either a project structure or a matrix structure. It should however, always be a formalized group of representatives from the engineering, production, maintenance, logistics and other related disciplines and a dedicated project manager or programme manager should always head this team.

A dedicated person responsible for managing and coordinating project obsolescence issues, as well as for supporting the project or programme during applicable investigations, resolution and implementation, should be appointed. The project team should work together to support specific project or programme goals and should also support activities to develop and implement solutions and strategies to resolve common component obsolescence problems.

Figure 2, as amended from Rooney [6], is an example to illustrate the composition and interfaces of a project team. This amended team structure clearly shows the multi-functional and multi-disciplinary nature of the team that can effectively support obsolescence resolution management. Many specialist members of the development team are drawn from within the company or existing project teams. It is however, important to include the customer and suppliers in the team. Customer involvement ensures that the requirements for the product or system are properly defined and the interfaces regarding obsolescence issues are established. Joining an external obsolescence-teaming group largely enhances the ability to address obsolescence issues more cost-effectively.

In bigger organizations, the requirement can exist to establish a dedicated obsolescence management team at organizational level with representatives from the projects/programmes and all related disciplines in the organization. This obsolescence management team should be headed by a dedicated obsolescence manager who must integrate and address obsolescence issues at organizational level and also be the interface to external component obsolescence teaming groups. Each affected/project programme could then share in the obsolescence resolution implementation costs and duplication of efforts could be limited to the mutual benefit of all. 
Sometimes, an organisation can have no specific projects or programmes, yet nevertheless have an interest in resolving obsolescence issues (e.g. development or support supplier companies, component manufacturer or component supplier companies). They should therefore appoint dedicated representatives to address the obsolescence issues related to their environment and to interface with other related obsolescence management teams or functions. In conclusion, the success of a formal project team depends largely on how effective design and supportive elements can address aspects related to design for performance, manufacturability (produce-ability), testability and maintainability, including component obsolescence mitigation.

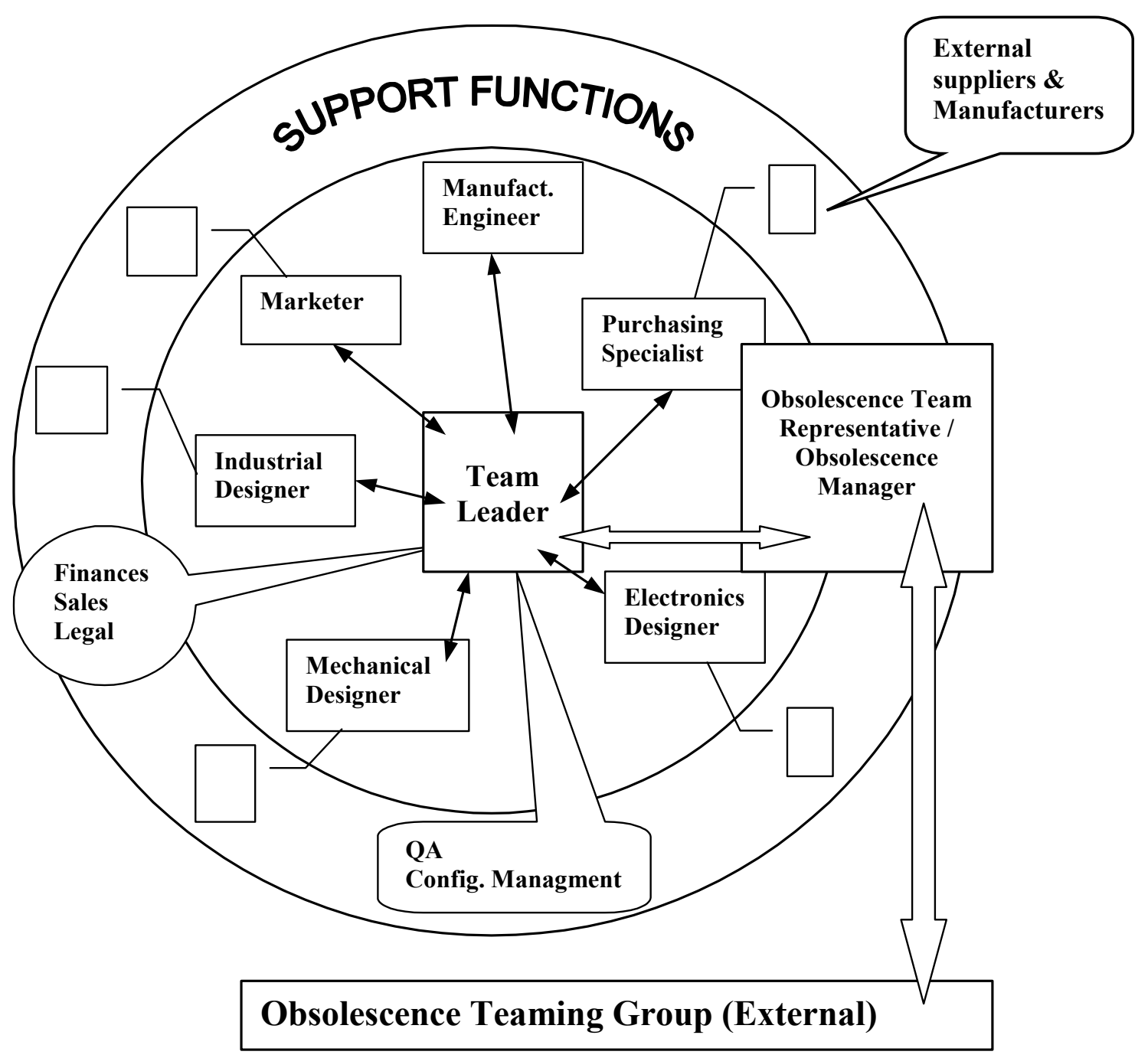

Figure 2: Typical product development team for a product of modest complexity

\subsection{Development of an obsolescence management plan (OMP)}

The project manager should produce and implement an obsolescence management plan (OMP) at the earliest stages of a project in order to describe the strategies for identification and mitigation of the effects of obsolescence throughout all stages of the product life cycle. [5] Typical OMP issues that should be addressed include the requirement to cover all materiel regardless of whether it has been developed for a specific project or customer, system or is a 
COTS product. OMP goals should be compatible with the project's/programme's current support arrangements and constraints. It must provide a clear basis on which obsolescence management requirements can be negotiated with suppliers, original equipment manufacturers (OEMs) and teaming partners in related or collaborative projects. Other unique issues for example, legal, safety and environmental factors or restrictions pertaining to international trade in arms, or other supplier terms and conditions applicable to the programme can also be applicable.

Three risk elements should be considered, namely impact, cost and probability, and each of these should be classified into three levels of severity: low, medium and high. The risk assessment related to the specific obsolescence problem would then determine the actions to be implemented. If the risks are low, the obsolescence management strategy can be to only monitor the situation and implement corrective actions as and when required (re-active strategy). Higher obsolescence risk assessment should be addressed without delay and an obsolescence case should be registered for each instance. [16]

When deciding on the strategy to implement, it is important to do a trade-off analysis considering value for money over the complete life cycle of the product and taking into account any cash flow constraints, as well as availability, maintainability and reliability requirements as applicable. The planned strategy should be included in the obsolescence management plan (OMP) and the implementation activities implemented as planned and not only when an urgent obsolescence problem arises.

\subsection{Project team obsolescence resolution implementation}

The obsolescence manager or representative for the project/programme should ensure the implementation of the most cost-effective solution when an item is identified as obsolete. This involves the evaluation of the alternative solutions and the actions to consider to resolve the issues. Before final implementation, a trade-off analysis must be done to consider the most cost-effective solution for the specific programme, and where applicable, for all related programmes or related organizational facilities. The following typical obsolescence management resolution steps may be considered for implementation by the project team: [16].

- Identify and verify obsolescence problems.

- Assess the impact on the system and logistics.

- Identify solution option candidates.

- Identify inventory sources or alternative supplier sources.

- Implement component standardization policies in order to reduce the variety of components and therefore the number of possible obsolescence problems.

- Identify feasible engineering solutions.

- Recommend solutions.

- Evaluate alternative solutions.

- Prioritise and schedule these solutions, and finally.

- Ensure funding to implement the selected solutions.

\subsection{Budgetary and other solution implementation considerations}

The total cost of obsolescence for a programme and the solution costs for each obsolete item 
should be determined. In evaluating any obsolescence solution implementation and especially for any redesign effort, the engineering team (consisting typically of design, manufacturing, and support personnel) should make sure to include all costs associated with the change. For budgeting exercises, programme managers and component manufacturers should quantify the total life cycle cost assumptions of each current and future obsolete component. To determine the high level cost of obsolescence for a system, specific questions should be answered. [13] How many items (or components) are currently obsolete? How many types of component could become obsolete next year and in subsequent years? How much would it cost to solve a problem for the obsolete components? How many failed components would be obsolete?

\subsection{Evaluation of alternatives and general trade-off analysis considerations}

Trade-off decisions to determine the impact upon the system as a whole should also be made after having performed an evaluation of alternative designs that involve software or alternative software support systems. Often, by the time that upgrades or modifications must be implemented, the compatibility with the new technology makes migration to the next configuration base line very complicated and often impossible (example; older XT and AT series computers operated on relatively small computing resources and basic operating systems such as DOS). Although these old computers or systems can today still provide the required performance in test equipment, the technology $(\mathrm{S} / \mathrm{W}$ and $\mathrm{H} / \mathrm{W})$ became obsolete. The problem is aggravated by the fact that original $\mathrm{S} / \mathrm{W}$ compilers, development platforms or $\mathrm{S} / \mathrm{W}$ versions are also prone to obsolescence or non-availability. Loss of the product knowledge base $(\mathrm{PKB})$ of older $\mathrm{S} / \mathrm{W}$, especially on legacy or older systems, becomes a major risk factor due to the fact that young $\mathrm{S} / \mathrm{W}$ developers are only familiar with current technology advanced $\mathrm{S} / \mathrm{W}$. Original developers on older $\mathrm{S} / \mathrm{W}$ moved on in life and the $\mathrm{PKB}$ on the older $\mathrm{S} / \mathrm{W}$ is lost.

The impact of the redesign of the software and the software support system contribute to system supportability and life cycle cost, (for example, the cost of training and tools, appropriately skilled manpower and software support contributes to overall system support costs). Trade-offs should be documented and updated if, and when, required through the total life cycle of the project to reflect latest estimates, revised assumptions and improved models. Trade-offs identified [17] relate to support system evaluations to address all hardware and software embodiment, pre-mission preparation, post-mission recovery and configuration management requirements. Evaluations and trade-offs should be conducted between predetermined block upgrades or modification programmes. Issues such as cost, response times, priorities, inter-operability, safety integrity, personnel and training requirements, tools and facilities must also be considered.

Trade-offs and evaluation of alternative system design implementations should receive appropriate consideration of their specific impact on software support. [17] (For example, revised system architectures may influence software support by affecting the number of software items, as well as the means by which they are configured or installed for operation). Manpower and personnel trade-offs should be considered when changes in hardware influence system software because they can impact on the skill levels required for software embodiment or pre-mission preparation.

When developing an obsolescence management strategy for COTS equipment, it is important 
to draw up a list of COTS items in the system because the design team must confirm information for each COTS item related to manufacturers' or supplier's procurement details. [7] Issues such as current availability, future production plans and planned upgrades should be important COTS component trade-offs in order to develop a COTS obsolescence management strategy and to limit potential obsolescence problems.

\subsection{The obsolescence solution decision process}

Important factors that affect the obsolescence solution decision process which must be considered, typically include [3]; Continued market and remaining life cycle for the product, manufacturability investigation of the LRU, potential for producibility enhancement, risk of current manufacturing processes becoming obsolete, risk of additional obsolete parts in the LRU, other LRUs affected by this obsolete part, impact of a redesign to product users, costs associated with having another LRU of different configuration status in the inventory, retrofit costs if the new LRU is not form, fit and function $(\mathrm{F}, \mathrm{F}, \mathrm{F})$ interchangeable and the economics of the decision need to be assessed.

Figure 3 derived from Mc Dermott et al [9] depicts a typical resolution decision process to use when an obsolescence notice is received for which the extent of obsolescence risk elements is not clear. The trade-off analysis as described in the previous paragraphs should be performed to decide on which solution options to implement.

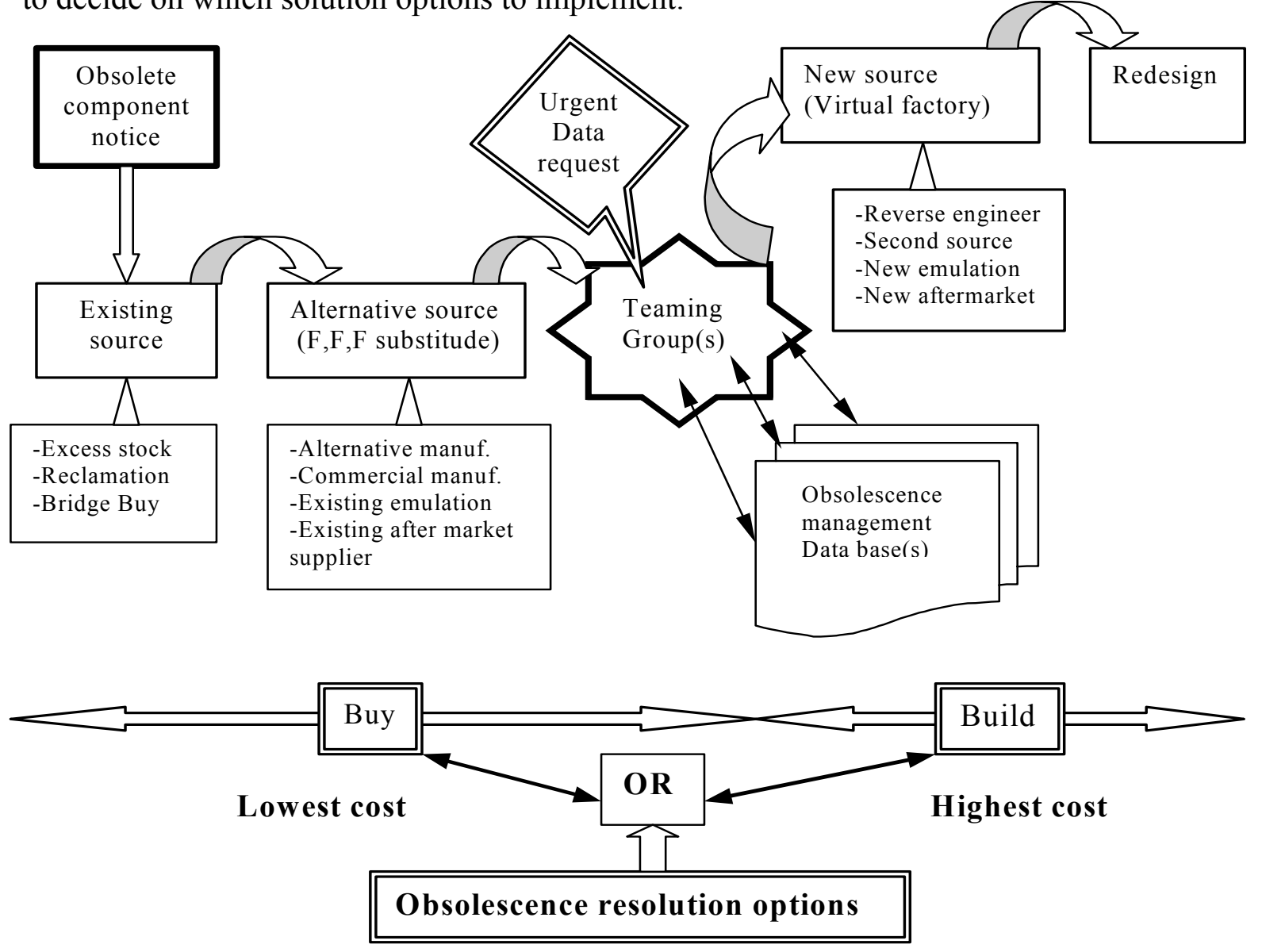

Figure 3: Selection process when the extent of obsolescence risk elements must be assessed 


\subsection{Obsolescence management monitoring and control}

Information technology to support decision-making, monitoring and control becomes increasingly important. Various obsolescence-teaming groups (OTG) have implemented applicable Internet web sites. These provide engineers, designers and procurement personnel with information on obsolete specifications, changes in part selections, as well as information about substitute components. [10] An operational management system (OMS) is an essential tool in the management of a system's support phase. It allows for effective closing of the management loop thus enabling the identification and quantification of problem areas and trends and is therefore very important for effective obsolescence management.

A failure reporting, analysis and corrective action system (FRACAS) should be implemented as an integral part of the OMS in the system support phase to facilitate system improvement. [6] The job card by definition already contains a number of FRACAS data fields that contain the maintainability data of the FRACA system. By implementing relatively minor extensions to the job card, it is possible to capture reliability data and obsolescence risk data as well. [19]

In some organisations, component obsolescence management can be undertaken by the supply support or materials management functions. In this case, it is their responsibility to monitor programmes or systems at predetermined intervals to identify pro-actively what corrective actions need to be implemented. A typical supply support analysis process was defined in the research to assess possible obsolescence risks. [20]

\section{CONCLUSION}

The research identified that a good obsolescence management programme enables the development of new approaches to adapting to the changing electronics market and to ensuring access to a supply of suitable components. From the research, it has also become evident that it is important to monitor the actions of the major role players and policy makers in the electronics environment when dealing with obsolescence issues.

The benefit of teaming among related projects or programmes in an organisation, or joining a formal obsolescence teaming group (OTG) should not be underestimated. The typical product development team, as amended in the research, provides a good platform for managers to interface with internal team members, as well as with external OTGs when resolving obsolescence risks.

Obsolescence cost drivers as defined in the research should be reviewed, and where applicable, managers should consider them when they decide on the appropriate obsolescence resolution options to implement. This should be done in a pro-active rather than re-active mode because the impact of component obsolescence on the availability of electronic systems in the military support environment has become an ever-growing problem. The research resulted in an approach to managing component obsolescence that is supported by the recommendations as listed below. It will enable managers that are confronted with obsolescence risks to implement applicable management actions and risk abatement strategies and to make team members aware of the problem of component obsolescence.

It can be concluded that whether to implement obsolescence management or not, is no longer the question because its benefit was demonstrated in several case studies [4,20]. It exceeded 
by far the costs associated with it. According to Haub [1], who has been involved in management of obsolescence for many years, it is those programme managers who have a comprehensive obsolescence management process in place to support their equipment, who know and praise its benefits, whilst the other managers fight obsolescence fires.

\section{RECOMMENDATIONS}

The following recommendations have been defined to ensure that component obsolescence risks are addressed in the military support environment and related electronic industries: $[11,20]$

- All programmes or major projects should define a process for dealing with obsolescence. An obsolescence management plan (OMP) should be developed per programme to address applicable obsolescence risk elements. The scope of the OMP may change, depending on the specific life cycle of the systems or equipment related to the specific programme.

- Addressing obsolescence risks and supporting obsolescence mitigation should be established as a performance metric, especially for critical personnel such as system engineers, electronic engineers, designers of electronic hardware and related software, logisticians, buyers and programme managers.

- Design engineers should use the concept of open systems and modular system architectures in new or updated designs. In other words, designs should enable the redesign or replacement of modular subsystems in a bigger assembly that will support form, fit and function $(\mathrm{F}, \mathrm{F}, \mathrm{F})$ upgrades.

- All applicable levels of management need to ensure that there is adequate funding for obsolescence mitigation, both for legacy and new systems. Additional funding is also required to support obsolescence teaming group activities and to support obsolescence solution recommendations, which may include specific component substitutions, requalifications, redesigns or last-time buys. In organisations without an obsolescence management programme, funds should be allocated for training and awareness campaigns at applicable levels.

- Component usage patterns should be monitored by component procurement managers and logisticians, especially for systems and equipment that must be supported for long periods of time. Applicable military sectors and the related defence industries should maintain close relationships with suppliers and single-source original equipment manufacturers.

- It is essential to characterize and document component functionality for systems, especially for aging systems, because technical data could be lost or become obsolete for those components approaching obsolescence. With the critical functionalities properly documented, it would be possible to use re-configurable or customized devices as a design option, or to do emulation on components to lower costs.

- A programme to effectively screen and/or eliminate high-risk components should be established, with the cooperation of the original manufacturers or suppliers. Effective communication channels should be established and maintained between all the parties 
concerned to mitigate the risks of obsolescence. This will expand the available obsolescence solution options when managers need to extend the life of systems or equipment and their incorporated components.

- The author proposes that the obsolescence strategy guidelines and related solution options as discussed in the article, be used as a guideline to develop a dedicated obsolescence management strategy for major programmes in the military electronic support and development environments.

- Possible subjects for further research related to this article include research on obsolescence management of all types of equipment and manufacturing process.

The author is currently busy with further research on a model to manage component obsolescence in the South African context. It will address a model for calculating the costs of obsolescence solution over the different life cycles of a system.

\section{LIST OF ABBREVIATIONS AND ACRONYMS}

$\begin{array}{lll}\text { COTS - } & & \text { Commercial off-the-shelf } \\ \text { COTG - } & & \text { Component obsolescence teaming group } \\ \text { ECP } & - & \text { Engineering change proposal } \\ \text { F,F,F } & - & \text { Form, fit and function } \\ \text { FRACAS } & - & \text { Failure reporting, analysis and corrective action system } \\ \text { H/W } & - & \text { Hardware } \\ \text { IC } & - & \text { Integrated circuit } \\ \text { LCC } & - & \text { Life cycle cost } \\ \text { LOT } & - & \text { Life of type } \\ \text { LRU } & - & \text { Line replaceable unit } \\ \text { MIL-STD } & - & \text { Military standard } \\ \text { OEM } & - & \text { Original equipment manufacturer } \\ \text { OMP } & - & \text { Obsolescence management plan } \\ \text { OMS } & - & \text { Operational management system } \\ \text { OTG } & - & \text { Obsolescence teaming group } \\ \text { PKB } & - & \text { Product knowledge base } \\ \text { QA } & - & \text { Quality assurance } \\ \text { S/W } & - & \text { Software } \\ \text { TLMP }- & & \text { Through life management plan } \\ \text { TLS } & - & \text { Through life support } \\ \text { USA } & - & \text { United States of America } \\ \text { USD } & - & \text { United States dollar }\end{array}$

\section{REFERENCES}

[1] F. Haub; "Managing Materiel Shortages the USN Way"; International Defence Review - Extra, Volume/Issue: 002/009, September 1997.

[2] L. Condra supported by D. Followell, G. Houchens, J. Jenks, M. Koehler, and Z. Porter; "Minimizing the Effects of Electronic Component Obsolescence"; Electronic Products Boeing Information Space \& Defence Systems, May 1998. 
[3] W.T. Hartshorn; "Obsolescence Management Process as a Best Practice"; Obsolete Parts Leverage Team Road Show, undated.

[4] Army Material Command; "Diminishing Manufacturing Sources and Material Shortages"; AMC-P 5-23, United States Army Materiel Command, Alexandria, Virginia, March 18, 1999.

[5] The Ministry of Defence, Directorate of Standardization; "Defence Standard 00-71, Issue 2: Obsolescence Management”; Defence Procurement Agency An Executive Agency of Kentigern House 65 Brown Street, Glasgow G2 8EX, 27 January 2001.

[6] A.C. Rooney; "Reliability Growth Management of Complex Electromechanical Systems"; Rand Afrikaans University, June 2000.

[7] The Defence Microelectronics Activity (DMEA); "Program Managers Handbook: Common Practices to Mitigate the Risk of Obsolescence", Revision D; Defence Microelectronics Activity (DMEA), 4234 54th Street, Bldg. 620, 31 May 2000.

[8] L. Condra (NDIA Paper. doc. 09/13/99); "Combating Electronic Component Obsolescence by Using Common Processes for Defence and Commercial Aerospace Electronics "; IECQ-CMC Avionics Working Group, 1999.

[9] DMEA: J. McDermott, J. Shearer and W. Tomczykowski; "Resolution Cost Factors for Diminishing Manufacturing Sources and Material Shortages”; ARINC, 2551 Riva Road, Annapolis, Maryland 21401, Revised May 1999.

[10] Northrop Grumman, Defensive Systems Division, Best Practice: "Components Obsolescence Management”; Northrop Grumman, Defensive Systems Division Rolling Meadows, IL Revision Date: 06/29/2001.

[11] Hamilton and Chin; "Aging Military Electronics: What Can The Pentagon Do?"; National Defence, March 2001.

[12] L. Condra, D. Followell, G. Houchens, J. Jenks, M. Koehler, and Z. Porter; "Minimizing the Effects of Electronic Component Obsolescence", Issue 2, 9/28/2000; Reprinted by AERO magazine by permission of The Boeing Company, 2000 .

[13] Z. Porter; "An Economic Method for Evaluating Electronic Component Obsolescence Solutions"; Electronic Products Boeing Information Space \& Defence Systems, May 1998.

[14] J.G. Martinez and P. Hueneme; "DOD ORR Teaming Group Process"; Working Group Meeting, Annapolis, Maryland, October 1998.

[15] N.B. Shawlee; "The Hidden Mil-Spec Spanner”; Avionics Magazine, vol. 22 no.5, May 1998.

[16] SI, The British Ministry of Defence Standards Department; "BS 7000-5 - Guide To Managing Obsolescence”; British Ministry of Defence, Latest issue.

[17] The Ministry of Defence, Directorate of Standardization; "Defence Standard 00-60 (Part 3) / Issue 2: Integrated Logistic Support Part 3 - Guidance For Application Software Support"; Defence Procurement Agency, An Executive Agency of Kentigern House 65 Brown Street, Glasgow G2 8EX31, March 1998.

[18] Kentron, Division of Denel (Pty) Ltd; P.O. Box 7412, Centurion 0046, Republic of South Africa.

[19] A. Wessels; "The Management of Reliability in a Multi-Level Support Environment"; Rand Afrikaans University, October 1997.

[20] A. Meyer; "Management of Component Obsolescence in the Military Electronic Support Environment”; Rand Afrikaans University, June 2002. 